\title{
NEIGHBOURHOOD SUSTAINABILITY ASSESSMENT MODEL FOR DEVELOPING COUNTRIES: A COMPREHENSIVE APPROACH TO URBAN QUALITY OF LIFE
}

\author{
TSELISO MOROKE, CAREL SCHOEMAN \& ILSE SCHOEMAN ${ }^{1}$ \\ ${ }^{1}$ Subject Group for Urban and Regional Planning, Mathematics and Applied Mathematics \\ North-West University (Potchefstroom Campus), South Africa.
}

\begin{abstract}
To this end, sustainability has progressively become a core principle and prerequisite in the urban planning and development. The application of sustainability and/or its principal expression is being threatened by neighbourhoods' inequality such as segregation in land use and varying levels of income in developing countries. From sustainable development perspective and strictly linked to spatial contexts, this reflects inadequate urban planning as these spatial and socio-economic inequalities translate to fragmented spatial systems, unsustainable urban form and low quality of life. The analysis of these variables depicts that between the rich neighbourhoods and poor neighbourhoods very little space is afforded for connectivity and integration, local facilities, environmental quality and spatial components which are themselves pillars of sustainable urban form and desired quality of life are not preferentially factored into poor neighbourhoods. Thus, bringing multiple and multifaceted adverse impacts on poor people such as living in the unsafe and unhealthy areas. In essence, locally provided community facilities, infrastructure and services are mechanisms of spatial transformation and integration thus promote social and economic development. When drawing up social services to act as the basis from which sustainability in urban areas could be determined - central contention is that urban sustainability cannot be achieved without adequate social facilities that are differentiated by neighbourhoods varying development densities, community size, mobility levels and socio-economic variations. As a result, this research paper evaluates the sustainability level of low-income neighbourhood living spaces which urban system requires in order to achieve urban sustainability. Evaluating neighbourhood sustainability requires a modelling and integrated approach that bring forward all aspects of urban development and quality of life. The Successful Neighbourhood Model (SNM) developed as the comprehensive sustainability assessment tool for low income neighbourhoods in pursuit of neighbourhood sustainability in South Africa is used. The application of SNM procedure embrace metric benchmarking methodology and this quantitative nature of sustainability assessment is employed to conclude and recommend timely integration of new urban sustainability issues in the planning policies, strategies and instruments. SNM has demonstrated that it is possible to identify barriers that hinder poor neigbourhoods to be sustainable and presents possibilities of aiding urban policy decisions regarding sustainability. Keywords: Neighbourhood, sustainability, quality of life, evaluation.
\end{abstract}

\section{INTRODUCTION}

The notion of quality of life and sustainability are the main subject of discussion. The study of quality of urban life has drawn increasing interest within urban planning [1]. As a point of departure this paper aims to address the notion of quality of life and attempts to understand its relationship with the notion of sustainable development. This includes deducing quality of life definition and dimensions with a focus on neighbourhood level as a special case. This specific mentioning is necessary as the desire to attain or improve quality of life can be individual or societal [2]. The society feature is of interest - it reflects on urban planning concern with the planning of settlements and communities [3] - substantiating neighbourhood planning as one approach of addressing the issues of public space and quality of life issues within the context of planning [4]. Therefore, principles of quality of life for a neighbourhood and 
- its determinants/dynamics/features of quality of life and measuring the quality of life and sustainability at neighbourhood level in low income developing countries are the main points of discussion in this paper. In order to unearth unbalanced nature and be able to identify rectification steps or interventions the neighbourhoods are used.

\section{QUALITY OF LIFE: AN OVERVIEW OF THE CONCEPT AND APPROACHES}

The quality of life is a complex, multifaceted construct that requires multiple approaches from different theoretical angles [5]. It fences and embraces fields of international development, healthcare, political science, built environment, urban planning, education, recreation and leisure time and social belonging [6]. This cross-disciplinary and multi-faceted nature of quality of life renders it complex concept with no clear or adequate or agreed upon definition. However, a common-basis is that the term quality of life describes all relationships and dynamics within a given concept framework. One of the core key factors of quality of life is the interactions between people and nature in a mutual and reciprocal quality - resulting in measurable changes both to people and to nature [7].

The objective of this paper is to the urban planning features/dynamics - ability of the quality of life dimensions for sustaining any urban development. The quality of life notion from urban development perspective is derivable from the efficient infrastructure systems that purveyances the delivery of goods, services and information and supports the area's physical, economic and social growth [8]. These urban quality of life attributes apply also to urban sustainability. Garau et al. [9] incorporate these aspects of sustainability in their definition of sustainable city - as a place that have a strong environmental focus with a balance within the city between infrastructures, information and communication technologies (ICTs), smart technologies, and urban metabolism - sewage, water, energy and waste management. Notably, quality of life attributes in the urban systems - within the context of urban planning have to coincide with sustainability requirements (economic, environmental, and social development) in order to deliver high quality of life. Attestation to this, the world has entered an urban era where sustainable development has taken the centre stage and cities as the context for preferred lifestyles, desired quality of life and stronger livelihood opportunities for inhabitants' future wellbeing [10]. This outlines a trade-off between the concept of quality of life and that of sustainability. To understand and articulate this relationship it is imperative to define sustainability and sustainable development.

\subsection{Sustainability definition}

There is a wide consensus among sustainability scholars and practitioners with a specific focus on fundamental principles: environmental, social and economic dimensions [11, 12] termed the three pillars of sustainability [1]. These principles are given depth and made operational through sustainability. It has emerged as the new field of science that seeks to ensure the endurance of systems and/or processes to maintain the quality of the sustainable development requirements such as balancing them (social, economic and environment requirements) [12] and sustained for an unforeseeable future [6]. On the flipside, it is argued that the terms sustainable development, sustainability and sustainable are sometimes overand misused because they allow various sustainability views to co-exist, random conceptualizations which do not respect the fundamental sustainability principles [11]. However, drawing on the origins, fundamental principles and terminologies of sustainability and sustainable development in the context of urban planning and systems - this study define 
the sustainable urban neighbourhood (case in study) as having the following characteristics: wide enough choice of housing and facilities; well connected to jobs and services by foot, cycling and public transport; increased integration of economic prosperity; social equity and cohesion; protecting the environment, highlighting good practice in design, local governance, retail services and stressing the importance of spatial planning framework. This working definition entwined by set of urban planning principles induce practical realisation of sustainability and quality of life in neighbourhoods.

\subsection{Quality of life as attributes of sustainability}

There are numerous existing theoretical constructs, performance measure indexes that are linked to (and/or purporting to measure) quality of life in diverse ways. To mention a few, some of the concepts and indexes that capture objective quality of life include: services quality (availa-bility, accessibility, affordability, coverage, etc.), liveability (stability, healthcare, culture and environment, education and infrastructure), economic variables (income, inflation, tax rate and unemployment, etc.) and public transport accessibility index lies in a comparative context too amongst other performance factor as means to measuring the level of urban quality of life. These same urban quality metrics/indicators can be used to measure different aspects of urban sustainability. As part of assessment, urban quality of life and sustainability concept indicators crystallises in each other [13]. Yet, to satisfy demands for objective and more sustaining quality of life it is important to take into consideration the dynamic complexity of cities - their dynamic systems with multiple interactions, relationships and consequences. The construct quality of life does not enable articulation of any casual inferences about the relationships/interactions among these variables - lacks ability to diverge diverse agendas. In contrast, sustainability emphasizes the integration (and/or it is an integrating concept) not just balance between spatial/environmental, social and economic qualities/requirements [14].

\section{INTEGRATING DIMENSIONS OF URBAN SUSTAINABILITY AND SETTING PARAMETERS FOR EVALUATION}

The integration of economic, social and environment dimension has to be directly connected with the issues of infrastructure services/public services and goods accessibility and availability, poverty alleviation, housing, spatial transformation and creation of equal opportunities to transform spatially fragmented cities into functional cities [10]. The lack of operational integration directly translates to poor land use-transport connection, myriad environmental issues and not a contributor to stimulate economy while practically exacerbating sporadic unplanned development along corridors. Identifying these strands of disintegration is imperative - this explains the significant gap that exists between neighbourhood sustain-ability concepts and the practical implementation of the idea. In essence, applications/policies and quality of life features that are disintegrated can hardly be called sustainable [15].

This analytical framework provides a base for assessment processes and comparative review of neighbourhood/city sustainability that aid decision making. As a result indicators that can respond to cities/neighbourhoods problems such as distorted neighbourhood growth direction, spatial inequalities and necessities, food security, demographic diversity, environmental degradation, socio-economic challenges and connectivity and mobility challenges can be selected [1]. It is worth noting that urban sustainability indicators abound and so do problems including them [16]. These include technical issues of normalization, weighting, and 
aggregation, as well as conceptual issues of indicator selection, boundary delineation, heterogeneity, scale and strong versus weak sustainability [16]. However, this system of indicators can be useful for developing qualitative and quantitative descriptors of urban environments [9]. They outline the potential of measuring the level of neighbourhood sustainability and initiating the assessment process or can be used to organise or construct themes/criteria/factors for sustainability assessment.

\subsection{Measuring urban neighbourhood sustainability}

On no account a single city can contribute to overall sustainability and quality of life if its own component parts are found not to be sustainable [17]. The cities have begun to focus on the neighbourhoods as the most appropriate scale to plan, deliver services and address unsustainable behaviour practices and norms [18]. More expressively, neighbourhoods are building blocks of the cities [19]. Sustainable neighbourhood is germane to the urban agenda for sustainable cities. As a result, the sustainability level of neighbourhood living spaces influence the overall sustainable urban development as it constitutes a major component of urban land use. However, the challenges remains measuring progress towards achieving urban planning policies/concepts/applications such as integrated sustainable urban develop-ment and sustainable modes of living as the degrees of sustainability initiatives are descriptive indicators. Parallel to (or as a result) this research is purposed to explore a comprehensive neighbourhood sustainability evaluation strategy - inclusive of urban systems concepts such as different spatial, economic and social perspectives, approaches, processes and integration strategies. In an attempt to claim urban sustainability measures the neighbour-hood becomes a good fit for this research paper as it is small enough as a means of assessment to permit comparisons to the situations and large enough to display meaningful impacts.

\section{NEIGHBOURHOOD SUSTAINABILITY ASSESSMENT TOOLS}

It is worth mentioning that there are a number of means of assessment tools that are established to assess neighbourhood sustainability. These methods represent a significant contribution to assess the sustainability levels of neighbourhood development. They have aggregated a considerable amount of information into indices for social, economic and environment dimensions as well as covering a wide range of urban planning issues such as transport and movement, built environment, governance, innovation and technology amongst others. This is what this paper intends to achieve - comprehensive assessment criteria illustrated by these methods. This includes scoring and weighing each theme and factor/issue in order to determine the best practice. In essence, they operationalise sustainability by providing performance benchmarks [1] and in turn aid comparative review of neighbourhoods, districts and cities sustainability level.

Nevertheless, these assessment tools discussed here, are not all-inclusive of neighbourhoods sustainability issues. The confinement of the tool methodology to the imperatives of the social, economic and environmental dimensions appears as the backdrop in a review of urban and regional planning literature. Sustainability related tendencies in urban areas suggest a different development path for the future of planning systems. This is based on arguments that sustainability issues are characterized by influential factors related to residential land use [21], community development, land use and planning, infrastructure services [22] and various segments including economic, social, institutional and cultural practices. This triggers concern to develop evaluation approaches in the field of urban development 
Table 1: Summary of neighbourhood sustainability assessment tools.

\begin{tabular}{|c|c|c|c|c|}
\hline Scheme & $\begin{array}{l}\text { BREEAM } \\
\text { Communities }\end{array}$ & $\begin{array}{l}\text { LEED- } \\
\text { Neighbourhood } \\
\text { Development }\end{array}$ & $\begin{array}{l}\text { CASBEE-City } \\
\text { (for Urban } \\
\text { Development) }\end{array}$ & $\begin{array}{l}\text { DGNB Urban } \\
\text { Districts }\end{array}$ \\
\hline Institution & $\begin{array}{l}\text { Build Research } \\
\text { Establishment } \\
\text { (BRE) }\end{array}$ & $\begin{array}{l}\text { US Green } \\
\text { Building } \\
\text { Council }\end{array}$ & $\begin{array}{l}\text { Institute for } \\
\text { Building Environ- } \\
\text { ment and Energy } \\
\text { Conservation }\end{array}$ & DGNB \\
\hline $\begin{array}{l}\text { Country of } \\
\text { Origin }\end{array}$ & UK & USA & Japan & Germany \\
\hline $\begin{array}{l}\text { Original \& } \\
\text { recent } \\
\text { version }\end{array}$ & 2008 and 2012 & 2009 and 2014 & 2006 and 2014 & 2012 and 2014 \\
\hline $\begin{array}{l}\text { Stages of } \\
\text { evaluation }\end{array}$ & $\begin{array}{l}\text { Design phase } \\
\text { (outline and } \\
\text { detailed designs) }\end{array}$ & $\begin{array}{l}\text { Planning, } \\
\text { design and com- } \\
\text { pletion phases }\end{array}$ & $\begin{array}{l}\text { Planning, design } \\
\text { and completion } \\
\text { phases }\end{array}$ & $\begin{array}{l}\text { Design phase } \\
\text { (outline and } \\
\text { detailed } \\
\text { designs) }\end{array}$ \\
\hline $\begin{array}{l}\text { Scale of } \\
\text { focus }\end{array}$ & $\begin{array}{l}\text { Neighbourhood } \\
\text { scale }\end{array}$ & $\begin{array}{l}\text { Neighbourhood } \\
\text { and district }\end{array}$ & $\begin{array}{l}\text { Neighbourhood, } \\
\text { district and city }\end{array}$ & $\begin{array}{l}\text { Neighbourhood } \\
\text { and district }\end{array}$ \\
\hline Core themes & $\begin{array}{l}\text { *Governance } \\
\text { *Socio- } \\
\text { economic } \\
\text { wellbeing } \\
\text { * Resources and } \\
\text { energy } \\
\text { *Land use and } \\
\text { ecology } \\
\text { *Transport and } \\
\text { movement } \\
\text { *Innovation }\end{array}$ & $\begin{array}{l}\text { *Smart location } \\
\text { and linkage } \\
\text { *Neighbour- } \\
\text { hood design } \\
\text { *Green infra- } \\
\text { structure and } \\
\text { buildings } \\
\text { *Innovation } \\
\text { *Regional } \\
\text { priority }\end{array}$ & $\begin{array}{l}\text { Site quality } \\
\text { *Environment } \\
\left(\mathrm{QuD}^{1}\right) \\
\text { *Society }\left(\mathrm{QuD}^{2}\right) \\
\text { *Economy } \\
\left(\mathrm{QuD}^{3}\right) \\
\text { Environmental } \\
\text { load of urban } \\
\text { development } \\
\left.\text { (CO } \mathrm{CO}^{2} \text { emissions }\right)\end{array}$ & $\begin{array}{l}\text { *Environment } \\
\text { quality } \\
\text { *Economic } \\
\text { quality } \\
\text { *Socio-cultural } \\
\text { and functional } \\
\text { quality } \\
\text { *Technical } \\
\text { quality } \\
\text { *Process } \\
\text { quality }\end{array}$ \\
\hline $\begin{array}{l}\text { Number of } \\
\text { issues }\end{array}$ & 41 & 56 & $\begin{array}{l}42 \text { (+environment } \\
\text { load) }\end{array}$ & $\begin{array}{l}45 \text { issues (now } \\
30 \text { ) }\end{array}$ \\
\hline $\begin{array}{l}\text { Issue } \\
\text { weighting }\end{array}$ & $\begin{array}{l}\text { Differentiated } \\
\text { Weight }\end{array}$ & $\begin{array}{l}\text { Differentiated } \\
\text { Weight }\end{array}$ & Equal Weight & $\begin{array}{l}\text { Differential } \\
\text { Weight }\end{array}$ \\
\hline $\begin{array}{l}\text { Performance } \\
\text { rating scale }\end{array}$ & $\begin{array}{l}\text { Outstanding }=85 \% \\
\text { Excellent }=70-84 \% \\
\text { Very Good }= \\
55-69 \% \\
\text { Good }=40-54 \% \\
\text { Pass }=25-39 \%\end{array}$ & $\begin{array}{l}\text { Platinum }=80 \% \\
\text { Gold }=60-79 \% \\
\text { Silver }= \\
50-59 \% \\
\text { Bronze = } \\
40-49 \%\end{array}$ & $\begin{array}{l}\text { Excellent }=60 \% \\
\text { Very Good }= \\
30-59 \% \\
\text { Good }=20-29 \% \\
\text { Fairly Poor }= \\
10-19 \% \\
\text { Poor }>10 \%\end{array}$ & $\begin{array}{l}\text { Platinum = } \\
80 \% \\
\text { Gold = 65-79\% } \\
\text { Silver = } \\
50-64 \% \\
\text { Bronze = } \\
35-49 \%\end{array}$ \\
\hline
\end{tabular}

Source: Callway et al. [20]. 
[21]. For example, there is a correlation between the urban spatial expansion (structure) and the changes in population size that set parameters for evaluation [23]. Moreover, the incorporation and integration of institutional [political] dimension in sustainability principles are invariably gaining significant attention. In essence, five dimensions of urban sustainability namely: social, economic, ecological, physical and political dimensions have been identified $[24,25]$. Arguably ecological and physical [spatial] are discussed jointly under environment dimension in much of literature review [26].

Without in-depth critical evaluation of the subjectivity of the scoring and weighting processes these mentioned deficiencies are enough proof that evaluation criteria of these tools are not coincident with the comprehensive assessment criteria this research desires to achieve. However, it is important to consider the information furnished by these assessment tools in preparing a comprehensive set of assessment criteria at the neighbourhood level that this paper aims to realize. Therefore, in preparing a pool of criteria related to sustainability at the neighbourhood level these systems can be modified. Formulate criteria and factors to measure different neighbourhoods' sustainability in a manner befitting the realities of their unique context. That is developing the model that covers a wide range of neighbourhood sustainability requirements and concerns based on rating system that offers the comparative review of sustainability utilising scoring and weighting.

\section{SUCCESSFUL NEIGHBOURHOOD MODEL (SNM)}

The modelling approach as a guiding tool for sustainability measurement is applied to provide perspective in assessing neighbourhoods sustainability, prioritising and ranking. The comprehensive neighbourhood sustainability-oriented performance measurement framework (Successful Neighbourhood Model (SNM)) is presented to provide comparative review and ranking of neighbourhood sustainability using its criteria and factors. The SNM is an approved model (see [27]) formulated for evaluating low income neighbourhoods sustain-ability within South African context and fit its conditions [1]. The neighbourhood is a back-bone of the model - as mentioned earlier, it is the most appropriate scale to execute sustain-able urban planning and development. Based on these dimensions neighbourhood unit is expected to provide sufficient account of sustainability indicators - relevant indicators in pursuit of sustainability practices that would allow measuring the level of neighbourhood sustainability performance [1]. While the rest of indicators are drawn from critical literature review of urban concepts, theories, systems, planning principles, fundamental principles of sustainable development and sustainability science (see [27]). The indicators are instrumental in collection, categorisation and analysis of data as well as formulation of qualitative variables.

Then, based on the processes, an indicator framework/criteria/theme is determined to frame chosen indicators that satisfy urban neighbourhood sustainability assessment require-ments. To carryout this, the word successful is used to design the frame and choose criteria. Its letters are segmented to represent and match each criterion concept set with respect to validity, practicality, relevance and importance to neighbourhood sustainability performance measurement requirements [27]. In essence, themes/criteria are identified, which in turn is divided into subthemes, for which in turn indicators are then identified. A total of ten themes are now spatial/ environment; urban density; culture and social; connectivity and mobility; economic; smart growth; service quality; food security; urban governance and liveability. Having this indicator framework - indicators weights are facilitated by applying appropriate MCA - selecting a particular indicator set over another (eliminating overlapping indicators and redefining based on themes relevance). To reduce the number of indicators or to reflect the integrative characteristics of a system, indicators are often combined through mathematical manipulations to produce 
Table 2: SNM - Refined SNM sustainability indicators.

\section{Indicator group Measurement of factor(s)}

\section{Spatial/environment}

Locational Average neighbourhood proximity to CBD at various categories: advantages/ opportunities

Excellent $(\leq 2.5 \mathrm{~km})$; Good $(2.501 \mathrm{~km}-5 \mathrm{~km})$; Moderate $(5.001$ km-7.5 km); Poor (7.501 km-10km); Insignificant (10.001 km+) Average neighbourhood proximity to work at various categories: Excellent $(\leq 2.5 \mathrm{~km})$; Good $(2.501 \mathrm{~km}-5 \mathrm{~km})$; Moderate $(5.001$ $\mathrm{km}-7.5 \mathrm{~km})$; Poor (7.501 km-10 km); Insignificant (10.001 km+)

Residential land use Residential land use (total \# of formal houses or brick structures on separate stands) /Business land use (total \# of business structures) $=\%$ of mix land use per neighbourhood

Urban density: Unequal distribution of urban population

Concentration ratio The proportion of inequality in the distribution of population in rela(CR) tion to the area $=$ The redistributed $\%$ of the city's population to produce an exact correspondence between population size and land area. Normalized neighbourhood concentration ratio $=\{$ Excellent $(0-0.2)$; Good (0.21-4.0); Moderate (0.41-0.6); Poor (0.61-0.8); Insignificant $(0.81-1.0)\}$.

\section{Cultural and social capital}

Inclusive planning 5 year neighbourhood involvement growth rate $=[$ Total $\#$ of people inand implementation volved in the neighbourhood regeneration project $\_\mathrm{t}$ - Total \# of people involved in the neighbourhood regeneration project_(t-5)]/[Total \# of people involved in the neighbourhood regeneration project_(t-5) $]=\%$ [Total \# of neighbourhood voting population]/[Total neighbourhood population] $=\%$ voting population per neighbourhood

[Total \# of citizens participating in community life and decision making]/[Total neighbourhood population] $=\%$ of community involvement

Social capital $\quad\{$ Total \# of social (organisations/activities) in neighbourhood $\} /\{$ Total \# of (organisations/activities) in the city $\}=\%$

Visitors $\quad\{$ Total \# of neighbourhood (hotels \& guest) rooms recorded $\} /\{$ Total \# of the city (hotels \& guest) rooms $\}=\%$

\section{Connectivity and public transport}

Public transport (\# public transport usage in residential neighbourhood)/(\# of public usage transport usage in all the residential neighbourhoods) $=\%$

Accessibility The neighbourhood average access time of public transport in terms of waiting time /The average (for all the neighbourhoods) access time of public transport in terms of waiting time $=\%$ of neighbourhood public transport access time per city

\{ Average daily \# of taxi available seats within 30 minutes or $2 \mathrm{~km}$ radius of the neighbourhood $\} /\{$ Total neighbourhood population $\}=\%$

Affordability and $\quad$ TTotal \# of households spending $>10 \%$ of income on transport fare $\}$ / payment \{Total \# of neighbourhood households $\}=\%$ of households spending more than $10 \%$ of income on transport fare 
Road infrastructure Road network $(\%)=\{$ Demand in terms of $\mathrm{km}$ of road to be tar in the neighbourhood $\} /\{$ Total neighbourhood road network in $\mathrm{km}\}$

Road maintenance demand $(\%)=\{$ Neighbourhood road high demand for maintenance in $\mathrm{km}\} /\{$ Total neighbourhood road network in $\mathrm{km}$ \}

Traffic convenience (Average neighbourhood travel time per day)/(Average travel time per day in all the residential neighbourhoods) $* 100=\%$

\section{Economic}

Economic charac- $\%=$ (The \# of people in the neighbourhood whose income is less than teristics $\$ 1.25$ a day)/(Neighbourhood population)

Measure the neighbourhoods household income by calculating the \% of the whole neighbourhood population that can be categories by social housing: No wage income (R0) fully subsidised; Very low income $(<\mathrm{R} 1500)$ fully subsidised ownership; Low income (R1500-R3500) Rental and partly subsidised ownership; Middle income (R3500-R7500) Rental; High income (R7500-R8001) No rental and ownership, gap housing

Human capital $\quad\{$ Residential neighbourhood employed \# $\} /\{$ Neighbourhood labour force (i.e. employed + unemployed) $\}=\%$

(Residential neighbourhood unemployed \#) /(Neighbourhood population $)=\%$

Economic vitality $\quad$ \# of the people that own the dwelling in which they live $\} /\{$ Total and market neighbourhood population $\}=\%$

\section{Smart growth}

Multiple transport Total \# of neighbourhood transport options/City transport options $=\%$ options

Range of housing opportunities

Sense of place

Total \# of neighbourhood residential dwelling houses options/Total $\#$ of city residential dwelling houses options $=\%$ of neighbourhood residential dwelling houses options

Total \# of people in the neighbourhood that is involved in public participation activities/Total neighbourhood population $=\%$ (\# of people living in the neighbourhood for more than 10 years)/ $($ Neighbourhood population $)=\%$

\section{Services (parks/sport fields/education/trans-port/housing services)}

Housing services coverage
(Total \# of households with piped water connection in the neighbourhood $) /($ Total \# of households in the neighbourhood $)=\%$ (Total \# of households with electricity connection in the neighbourhood $) /($ Total \# of households in the neighbourhood $)=\%$

(Total \# of households with access to refuse removal)/(Total \# of households in the neighbourhood) $=\%$

(Total \# of households with flush toilets in neighbourhood)/(Total \# of households in the neighbourhood) $=\%$

Urban housing $=($ Current demand for RDP housing in neighbourhood) $/($ Current demand for RDP housing in the urban area $)=\%$

Accessibility index Average travel distance $(\mathrm{km})$ for (facility/service)

$\%$ of neighbourhood beneficiaries (target population) within $3 \mathrm{~km}$ of facilities 


\begin{tabular}{ll}
\hline & $\begin{array}{l}\% \text { of neighbourhood beneficiaries (target population) within 5km of } \\
\text { facilities } \\
\text { Worst case travel distance }(\mathrm{km}) \text { for (facility/service) }\end{array}$ \\
$\begin{array}{l}\text { Food security } \\
\text { Availability }\end{array}$ & $\begin{array}{l}\text { (Total \# of households in the neighbourhood that are involved in food } \\
\text { production)/(Total \# of households in the neighbourhood) }=\% \\
\text { (Total \# of community functional food production projects in neigh- } \\
\text { bourhood)/(Total \# of community functional food production projects } \\
\text { in all the residential neighbourhoods) }=\%\end{array}$ \\
Urban governance
\end{tabular}

\section{Uuman capital}

Human capital Measure the local municipality human capital by considering: Shortage; Specialise skills; Implementation capacity; Provisioning for all specialised skills and Outsourcing to consultants

Database

Measure local municipality database by considering: Updating consistency; Reliability; Integration between the different spheres of government; GIS data; Completeness in terms of land use data, service data and transport data

Integration between/within the Measure the integration between/within the three spheres of governthree spheres of ment in terms of: Linkages between the planning in the three spheres government of government and the IDP; Linkages between the programs in the three spheres of government and the IDP; Linkages between the budgets in the three spheres of government and the IDP; Integrated monitoring of expenditure on all three spheres of government; Integrated monitoring on all three spheres of government if programs/projects are finished (on time and within projected budget

Elimination of Measure the local municipality backlogs in: Piped water connections; backlogs Electricity connections; Refuse removal; Flush toilets; RDP housing Operational factors Measure the local municipality operational factors in terms of: Operators adequate training or professional competency; Information systems effectiveness in monitoring operations; Timelines and professional competency; Operations budget to actual financial variance for major budget categories; Level of communication or understanding by decision makers

Maintaining existing infrastructure

(\# of days per annum that any residential neighbourhood in the urban area were without water $=0)+(\#$ of days per annum that any residential neighbourhood in the urban area were without water=1) + (\# of days per annum that any residential neighbourhood in the urban area were without water=2) + (\# of days per annum that any residential neighbourhood in the urban area were without water=3) + (\# of days per annum that any residential neighbourhood in the area were without water $>3$ )

Infrastructure Measure the local municipality infrastructure programs and projects programs and projects by considering: Prioritised projects before budget distribution; Timeously planning and design of new infrastructure; Changes in the urban form(growth and spatial changes); Current \& future traffic congestion levels; Areas where there is a need for congestion management 


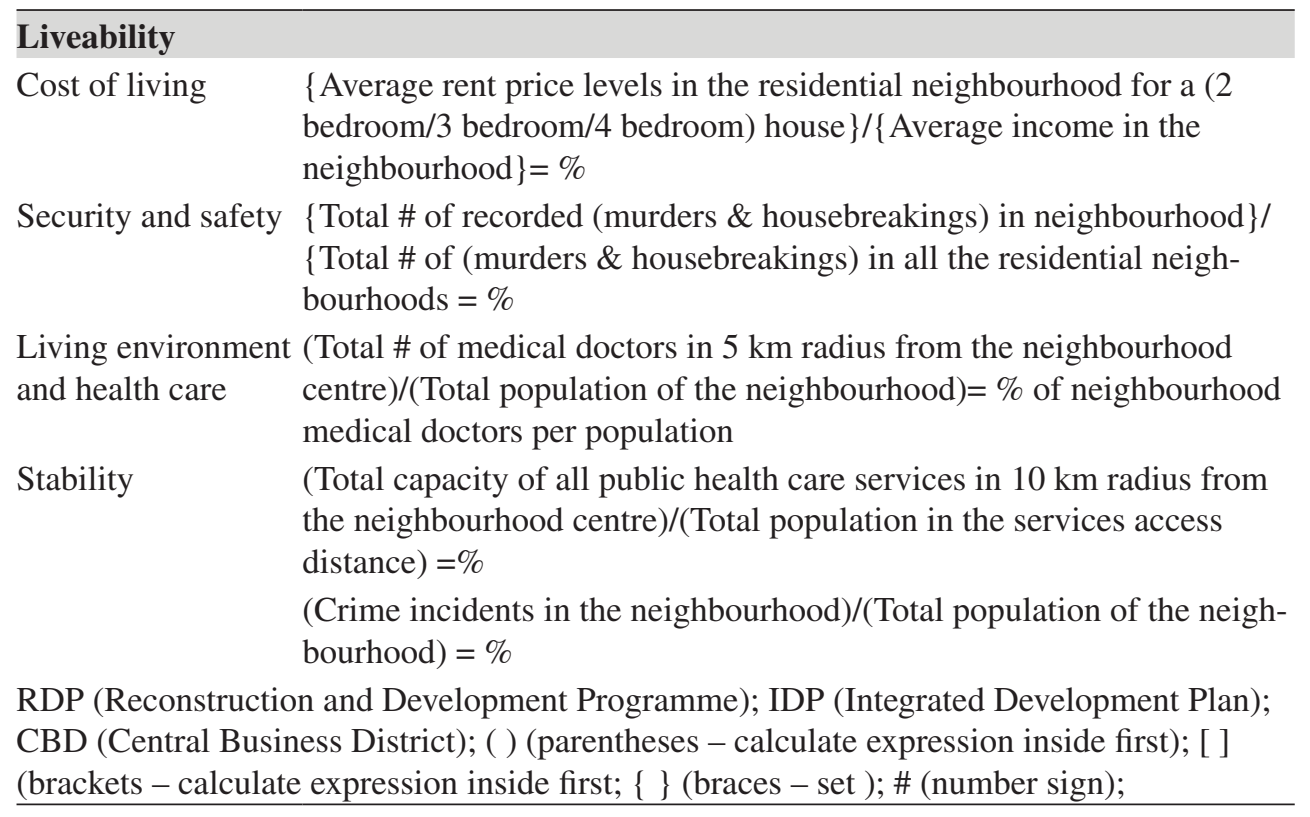

Source: Moroke et al. [27].

indices [28]. The utility of these criteria is composed into the neighbourhood sustainability index. Based on rating system that offers the comparative review of sustainability utilising scoring and weighting - the assessment process can then highlight the successful and less successful determinants of sustainability-related requirements and/or areas of low or high performance.

\subsection{SNM measuring system - Multi Criteria Analysis (MCA)}

Measuring the neighbourhood sustainability level denotes integration of the strategies and different metric systems. As it is often the case a single criterion is insufficient to assess a set of available alternatives [29]. The diversity of neighbourhood factors that comprise the criteria of sustainability assessment impose difficulties in terms of setting measures that describe a complex social, economic or physical realty. As it is the case here, the criterions and factors are multiple and conflicting in terms of being measured on many different metric systems they need to be analysed with respect to a set of normalised criteria. The systematic approach followed in this paper includes careful consideration of criteria selection, weighting and ranking.This rating, incorporates all the criteria on the same units, aggregates all partial scores into a single score and converts data to standardized quantitative data to allow some type of weighted analysis and comparison between criterions.

The process, which is a special case of the general vector optimization process, is based on a hierarchical aggregation procedure combined with an analysis function (like the linear additive method) [30]. The MCA process (see [31, 32, 33, 34]) allows the user to measure the consistency of the preference (of relative importance of the different criteria or factors) in a formal systematic way that will reduce the complexity and subjectiveness [34].

This paper purveys a composite neighbourhood sustainability index which calculates and describes the variation of neighbourhood sustainability (such as highlighting areas of low or high performance). 


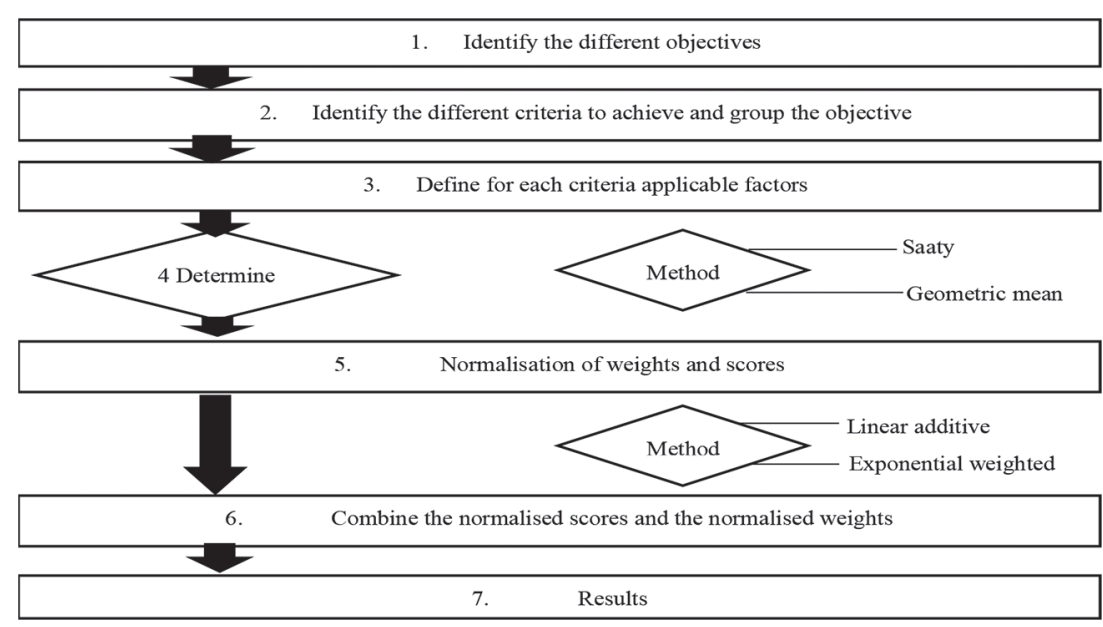

Figure 1: Process steps for calculating sustainability index.

Source: Schoeman [30].

\section{SNM APPLICATION - COMPARATIVE REVIEW AND RANKING OF NEIGHBOURHOOD SUSTAINABILITY}

For measurement purposes the weights are assigned to the criteria different themes and factors. This is done by combining the weights and the different values through the analytical process exponential weighted method or weighted sum method in the process which is employed to derive utility assigned to criteria in order to describe the relative sustainability of each of these criteria [27]. Then, each objective weight under a given criterion/theme and factor are normalised [35] - in basic terms, weighting integrate criterion multiple objectives into single objective where the numeric value determine relative importance or according to Zeferino et al. [36] set the priorities for the decision criteria. Each weighting criterion can be assessed against another. Based on the outcome simulated results the decision-makers and planners will be able to rank different criteria by order of importance.

\subsection{The case study application}

The case study is the City of Matlosana Local Municipality (CMLM). The CMLM is located in DR Kenneth Kaunda District Municipality (DR KKDM) in the North West Province, South Africa. The CMLM consists of five major towns that are Hartbeesfontein, Klerksdorp, Orkney and Stilfontein. Each of these towns has a township (expect Klerksdorp with two) namely: Tigane [Hartbeesfontein]; Jouberton and Alabama [Klerksdorp]; Kanana [Orkney] and Khuma [Stilfontein] These townships were originally developed in terms of the Group Areas Act as separate dormitory townships with each township having its intermediate size centre. The aim for the CMLM based case studies is to compare neighbourhoods with each other and provide a platform to promote urban neighbourhoods' sustainability assessment. The neighbourhood case studies are assessed using the above process allowing each case to be compared by area of sustainability measure and ranking. The sustainability assessment applications include highlighting areas of low or high performance and case studies comparisons and ranking. 


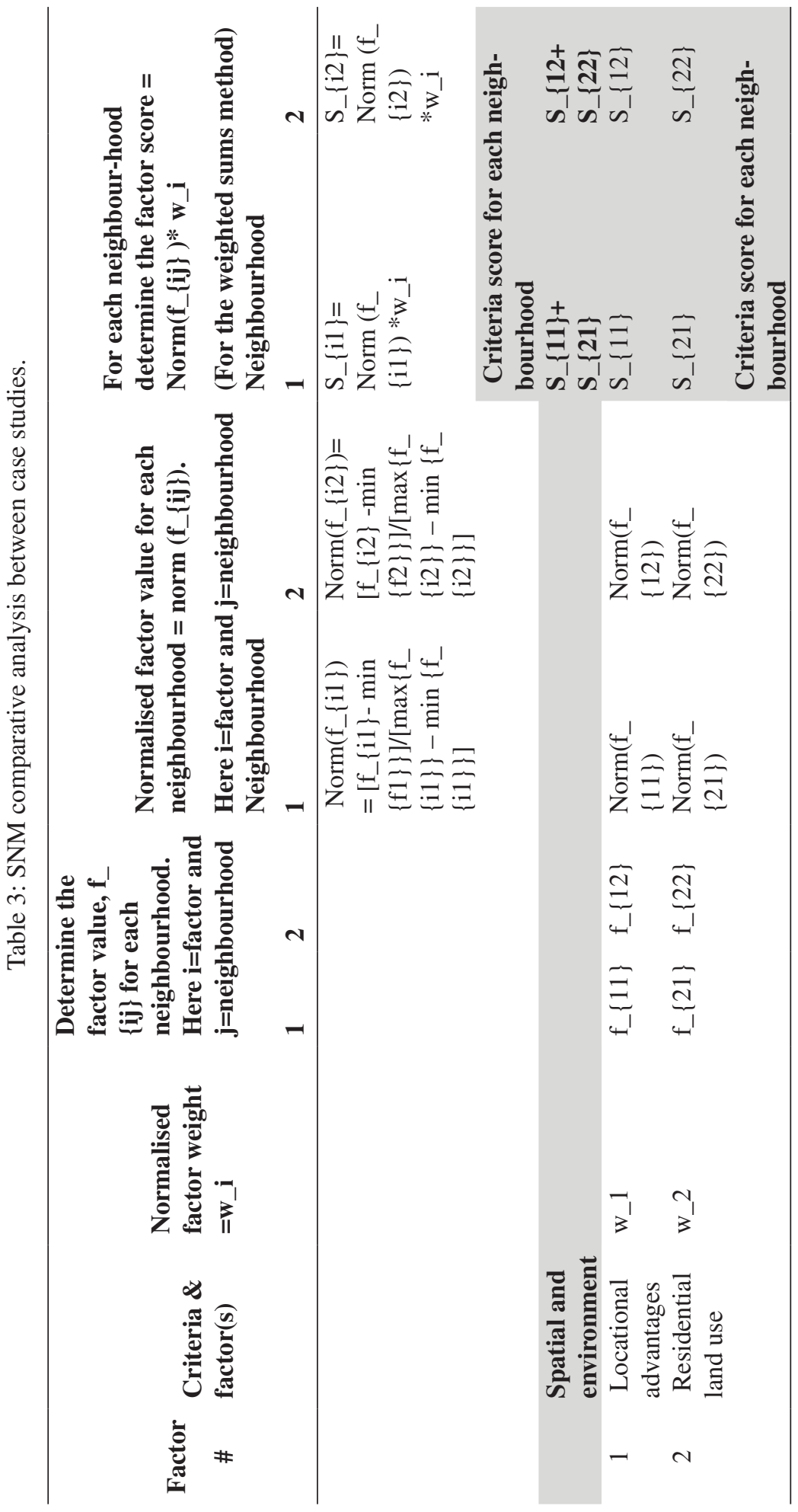




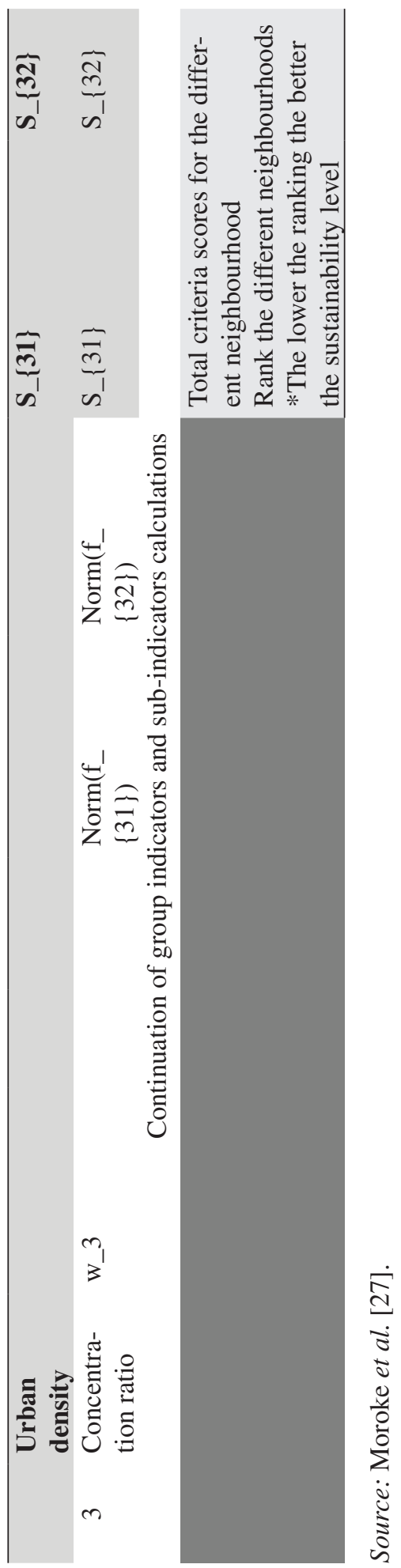




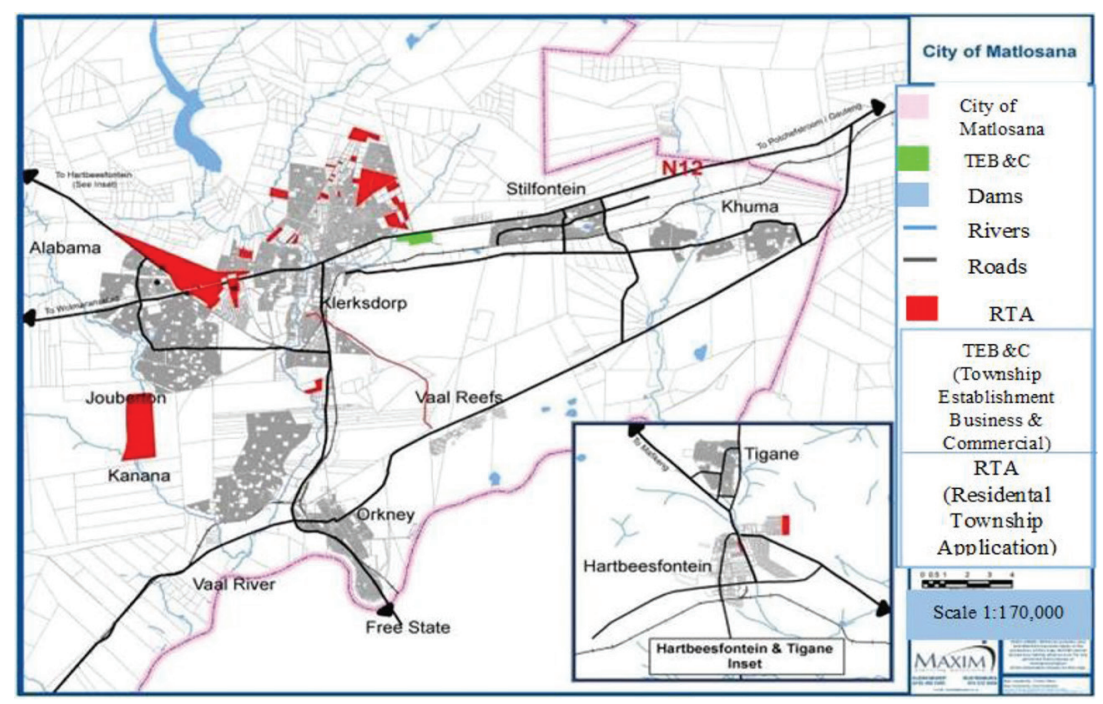

Figure 2: Case studies locality. Source. City of Matlosana [37]).

\subsection{Results}

Based on the rating system the values of criteria are aggregated to give the total score. The results as presented by SNM assessment process reveal priority areas and conditions of these five case study neighbourhoods. Each criterion value represents the sum of its factors

Table 4: Neighbourhood sustainability ranking by criteria.

\begin{tabular}{lcccccccccc}
\hline \multirow{2}{*}{ Criteria \& factor(s) } & \multicolumn{3}{c}{ Weighted sum method } & \multicolumn{6}{c}{ Exponential weighted method } \\
& Ala & Jou & Kan & Khu & Tig & Ala & Jou & Kan & Khu & Tig \\
\hline $\begin{array}{l}\text { Spatial and } \\
\text { environment }\end{array}$ & 3 & 2 & 4 & 1 & 5 & 3 & 2 & 4 & 1 & 5 \\
Urban density & 1 & 5 & 4 & 3 & 2 & 1 & 5 & 4 & 3 & 2 \\
Cultural and social & 5 & 1 & 4 & 3 & 2 & 5 & 1 & 4 & 3 & 2 \\
capital & & & & & & & & & & \\
Connectivity and & 3 & 2 & 1 & 4 & 5 & 2 & 3 & 1 & 4 & 5 \\
public transport & & & & & & & & & & \\
Economic & 5 & 3 & 4 & 1 & 2 & 5 & 3 & 4 & 1 & 2 \\
Smart growth & 3 & 5 & 2 & 4 & 1 & 3 & 5 & 2 & 4 & 1 \\
Services & 5 & 1 & 4 & 3 & 2 & 5 & 1 & 3 & 4 & 2 \\
Food security & 5 & 1 & 1 & 1 & 1 & 5 & 1 & 1 & 1 & 1 \\
Urban governance & 1 & 4 & 5 & 3 & 2 & 1 & 4 & 5 & 3 & 2 \\
Liveability & 2 & 1 & 3 & 4 & 5 & 2 & 1 & 3 & 4 & 5 \\
\hline
\end{tabular}

Source: Moroke et al. [27]. 
(exponential weighted) scores for each neighbourhood. Based on the rating system the values of criteria are aggregated to give the total score. The rank has five levels of categories from 1 to 5 - and designated as respectively the highest and lowest level of performance.

Based on the total criteria values the neighbourhood which has the highest points denotes rank 1 - for instance the highest level of sustainability performance and vice versa. In addition to the foregoing, 1, which is the most successful neighbourhood represents Jouberton, while 5 is the least successful neighbourhood and represents Kanana. Both weighted sum method and exponential weighted method give the same results in this regard. The outcomes of these methods differ in criteria connectivity and public transport and service with two neighbourhoods exchanging ranking order. Based on criteria the high performance areas (1) and most critical areas of concern (5) are highlighted with respect to neighbourhood sustainability. Therefore, Kanana neighbourhood which is ranked at 5 and Tigane neighbourhood at 4 signify the lowest level of sustainability performance. The criteria and factors determined by both methods indicate that Kanana needs immediate attention as its criteria and factors are on average 4 and the worst criterion is urban governance. However, the best scores are connectivity and public transport and food security at 1 followed by smart growth at 2 and liveability at 3 . In the case of Tigane ranking 4 the worst scores are criteria-spatial and environmental, connectivity and public transport and liveability at 5 , while the best score criterion is food security at 1 and criteria urban density, cultural and social capital, economic, services and urban governance at 2 .

The weighted sum method ranks Khuma 2 and Alabama, 3 while the exponential weighted methods are vice versa. Alabama's worst criteria scores in both methods are cultural and social capital, economic, services and food security at 5. Alabama's best criteria scores are urban density and urban governance at 1 followed by liveability at 2 . In the case of Khuma the worst criteria scores are connectivity and public transport, smart growth and liveability at 4, while the best criteria scores are spatial and environment, economic and food security at 1. Jouberton which ranks 1 most critical criteria of concern are urban density and urban growth at 5 followed by urban governance at 4 . The best criteria scores are cultural and social capital, services, food security and liveability at 1 followed by spatial/environmental and connectivity and public transport at 2 .

\section{CONCLUSIONS}

The quantitative assessment of sustainability provides means to benchmark the planning policies, strategies and instruments to determine their efficiency in performing their functions and activities. The criteria used suggest improvements in neighbourhood areas of concern such as service quality, public transport, spatial settings and urban governance among others.

An important lesson learned is that utility of criteria and neighbourhood(s) sustainability performance can be used to identify weaknesses in planning policies, strategies and instruments. From these findings, provide the answer(s) to decision making, and decision makers, planners and researchers to how to tackle unsustainable practices in neighbourhoods and other unprecedented challenges.

\section{RECOMMENDATIONS}

Utilise assessment frameworks/models to review the relevance and response of urban policies and planning frameworks to urban challenges. Considering that major shifts and stringent measures underway in land management principles (such as land reforms) and urban governance - it is recommended that urban policies be quantified or subjected to assessment frameworks to review or determine efficiency and effectiveness of new planning instruments 
and approaches in a concerted effort to tackle old and new challenges related to exclusion, socio-economic inequality and poverty inter alia. Policy that has objectives that comply and/ or confine to numerous criteria is interpreted to signify a more strategic approach and illustrating importance in pursuit of sustainability.

Enhance and focus implementation plans at the local government scale/level. Due to the scale of the local government, particularly its cities and neighbourhoods - the review of urban policies could be comprehensive or, better still, oriented to the realities, interests, emerging issues of urban inequalities and could be replicated on a broader scale (national level).

\section{REFERENCES}

[1] Moroke, T., Schoeman, C.B. \& Schoeman, I.M., Integrative and modelling approach to sustainability modes of living and neighbourhood development. WIT Transactions on the Built Environment, 179, WIT Press, 2018, https://doi.org/10.2495/ug180141

[2] Steyn, J. \& Van Greunen, D., ICTs for Inclusive Communities in Developing Societies, Cambridge Scholars Publishers, Newcastle, 2015.

[3] Barton, H., Sustainable Communities: The Potential of Eco-Neighbourhoods, Earthscan, London-New York, 2013.

[4] El Din, H.S. \& Elariane, S.A., Principles of urban quality of life for a neighbourhood, HBRC Journal, 9(1), pp. 86-92, 2013. https://doi.org/10.1016/j.hbrcj.2013.02.007

[5] Theofilou, P., Quality of life: Definition and measurement. Europe's Journal of Psychology, 9(1), pp. 150-162, 2013. https://doi.org/10.5964/ejop.v9i1.337

[6] Lotfi, S. \& Solaimani, K., An assessment of urban quality of life by using analytic hierarchy process approach. Journal of Social Science, 5(2), pp. 123-133, 2009. https://doi. org/10.3844/jssp.2009.123.133

[7] Fuller, R.A. \& Irvine, K.N., Interactions between people and nature in urban environments. Urban Ecology, pp. 134-171, 2010.

[8] Suharto, T., Tan, Y. \& Severine, M., Social infrastructure planning and sustainable community: example from South East Queensland, Australia. World Journal of Social Sciences, 1(4), pp. 23-32, 2011.

[9] Garau, C. \& Pavan, V.M., Evaluating urban quality: Indicators and assessment tools for smart sustainable cities. Sustainability, 10(3), pp. 575-593, 2018. https://doi. org/10.3390/su10030575

[10] UN-Habitat. Global Activities Report 2017.

[11] Waas, T., Huge, J., Verbruggen, A. \& Wright, T., Sustainable development: A bird's eye view, Sustainability, 3(10), pp. 1637-1661, 2011. https://doi.org/10.3390/su3101637

[12] Ceschin, F. \& Gaziulusoy, I., Evolution of design for sustainability: from product design to design for system innovations and transitions. Design Studies, 47, pp. 118-163, 2016. https://doi.org/10.1016/j.destud.2016.09.002

[13] Turkoglu, H., Sustainable development and quality of urban life, Procedia - Social and Behavioral Sciences, 202,pp. 10-14, 2015. https://doi.org/10.1016/j.sbspro.2015.08.203

[14] Council of Europe, Parliamentary Assembly. Documents de Séance, 7-8, 2003.

[15] Marshall, D. \& Danister, D., Land use and Transport, Elsevier, Amsterdam, 2009.

[16] Huang, L., Wu, J. \& Yan, L., Defining and measuring urban sustainability: A review of indicators. Landscape Ecology, 30(7), pp. 1175-1193, 2015. https://doi.org/10.1007/ s10980-015-0208-2

[17] Choguill, C. L., Developing sustainable neighbourhoods. Habitat International, 32(1), pp. 41-48, 2008. https://doi.org/10.1016/j.habitatint.2007.06.007 
[18] Zhang, Q., Yung, E.H.K. \& Chan, E.H.W., Towards sustainable neighbourhoods: challenges and opportunities for neighbourhood planning in transitional urban China. Sustainability, 10(2), pp. 406-429, 2018. https://doi.org/10.3390/su10020406

[19] Van den Berg, M., City children and genderfied neighbourhoods: The new generation as urban regeneration strategy. International Journal and Regional Strategy, 37(2), pp. 523-536, 2013. https://doi.org/10.1111/j.1468-2427.2012.01172.x

[20] Callway, R., Dixon, T. \& Nikolic, D., Breeam Communities: Challenges for Sustainable Neighbourhood Evaluation, RICS COBRA, London, 2016.

[21] Cao, X., Mokhtarian, P.L. \& Handy, S.L., Do changes in neighbourhood characteristics lead to changes in travel behaviour?: A structural equations modelling approach. Transportation, 34(5), pp. 535-557, 2007. https://doi.org/10.1007/s11116-007-9132-x

[22] Nolon, J.R., Compendium of Land Use Laws for Sustainable Development, 2006.

[23] Xu, Z. \& Coors, V., Combining system dynamics model, GIS and 3D visualization in sustainability assessment of urban residential development. Building and Environment, 47, pp. 272-287, 2012. https://doi.org/10.1016/j.buildenv.2011.07.012

[24] Barelkowski, R., Strategies for the identity of sustainable suburbs. WIT Transactions on Ecology and the Environment, 191, pp. 667-679, 2014.

[25] Allen, A., Sustainable cities or sustainable urbanisation? mycourses.aalto.fi (accessed 16 September 2013).

[26] Haapio, A., Towards sustainable urban communities. Environmental Impact Assessment Review, 32(1), pp. 165-169, 2012. https://doi.org/10.1016/j.eiar.2011.08.002

[27] Moroke, T., Schoeman, C.B. \& Schoeman, I.M., Developing a neighbourhood sustainability assessment model: An approach to sustainable urban development, Sustainable Cities and Society, 48, p. 101433, 2019. https://doi.org/10.1016/j.scs.2019.101433

[28] Wu, J. \& Wu, T., Sustainability indicators and indices: An overview, http://citeseerx.ist. psu.edu, (accessed 26 January 2018).

[29] Ishizaka, A. \& Siraj, S., Are multi-criteria decision-making tools useful? An experimental comparative study of three methods. European Journal of Operational Research, 264(2), pp. 462-471, 2018. https://doi.org/10.1016/j.ejor.2017.05.041

[30] Schoeman, I.M., The Use and Application of Vector Optimization Methods for Land Use and Transportation Integration (In Transportation, Land Use and Integration), WIT Press, 2017.

[31] Saaty, T.L., The Analytic Hierarchy Process, McGraw Hill, New York, 1980.

[32] Saaty, T.L., How to make a decision: The analytic hierarchy process and its applications. European Journal of Operational Research, 48(1), pp. 9-26, 1990. https://doi. org/10.1016/0377-2217(90)90057-i

[33] Saaty, T.L., Decision Making for Leaders, Pittsburgh, RWS Publications, 2001.

[34] Saaty, T.L. \& Vargas, L.G., Models, Methods, Concepts and Applications of the Analytic Hierarchy Process, Boston, Kluwer Academic Publications, 1984.

[35] Kiker, A.K., Bridges, T.S., Varghese, A., Seager, T.P. \& Linkovd, I., Application of multicriteria decision analysis in environmental decision making. Integrated Environmental Assessment and Management, 1(2), 95-108, 2005. https://doi.org/10.1897/ ieam_2004a-015.1

[36] Zeferino, J.A., Coceicao-Cunha, M. \& Antunes, A.P., Siting and sizing the components of a regional wastewater system: A multiobjective approach. Ecology and the Environment, 103, WIT Press, 2007.

[37] CoM (City of Matlosana). Township regeneration strategy, 2013. 